\title{
How a transformational Collective Benefit Mindset experience prompted parents raising children with disability to launch a peer network
}

Dr. Annick Janson ${ }^{(1)}$, Centre for Applied Cross-cultural Research, Victoria University of Wellington, New Zealand

Sylvana Mahmic, CEO, Plumtree Children's Service Inc., Marrickville, NSW, Australia

Trisha Benge, Director, McKenzie Centre, Hamilton, New Zealand

Colene Herbert, General Manager, Midland Region, CCS Disability Action, New Zealand

(1) annick.janson@egl.ac.nz

$\begin{array}{lr}\text { Abstract } & 1\end{array}$

$\begin{array}{lr}\text { Introduction } & 2\end{array}$

$\begin{array}{ll}\text { Benefit Mindset } & 2\end{array}$

Connecting individual mindshift to collective good: Wellbeing, flourishing and empowerment 2

The "epic" opportunity 3

$\begin{array}{ll}\text { Method } & 3\end{array}$

$\begin{array}{ll}\text { Participants and program } & 3\end{array}$

$\begin{array}{ll}\text { Measures } & 5\end{array}$

\begin{tabular}{lr} 
Results & 6 \\
\hline
\end{tabular}

$\begin{array}{lr}\text { Flourishing } & 6\end{array}$

PERMA profiles and action-oriented outcomes $r$

$\begin{array}{lr}\text { Contributing and building community } & 10\end{array}$

$\begin{array}{lr}\text { Discussion } & 11\end{array}$

Positivity as an engine for individual change $\quad 12$

Group self-transformation towards a Benefit Mindset $r$

$\begin{array}{lr}\text { Framework for analysis } & 13\end{array}$

$\begin{array}{ll}\text { Implications } & 14\end{array}$

$\begin{array}{ll}\text { Limitations } & 14\end{array}$

$\begin{array}{lr}\text { Conclusion } & 14\end{array}$

$\begin{array}{lr}\text { References } & 14\end{array}$

\begin{abstract}
This research reports how families forged their pathway towards a 'Benefit Mindset' self-transformation. This resulted in parents creating a peer network, taking steps to pursue their development and to share their learning about empowerment and flourishing as they work in parallel to create better outcomes for their children with disability.
\end{abstract}

Twenty-three participants (11 couples and 1 mother) raising children with disability or developmental delays attended the Now and Next ${ }^{\mathrm{TM}}$ program, which pioneered the integration of Positive Psychology in the disability sector. This disruptive program was launched in New South Wales in 2015 by two professionals with lived experience and evolved through co-design with the 300 families that have since completed the program (Mahmic \& Janson, 2018).

As participants grew their individual empowerment, hope and collective capacity, their vision to support other families and the collective mindset to make it happen emerged. These families recognised that the missing link in partnerships between professionals and families is their accountability in building their leadership.

Participants learnt about identifying their signature strengths and putting them to work to build their family leadership.

This research extends the concept of Benefit Mindset proponed by Buchanan and Kern (2017) about individuals to a group space by detailing how their Collective Benefit Mindset emerged. 


\section{Introduction}

Can we change our future by changing the way we think about it? What happens when a group of parents raising a child with disability or developmental delay seize an opportunity to radically change their perspective on their life and build a positive vision for their child and family?

This research documented, in real time, the individual mindshifts that parents underwent, shedding some light on the possible "active ingredients" that could fuel the group transformational shift in thinking that may underpin their future actions.

\section{Benefit Mindset}

McEwen and Schmidt (2007) defined mindset as the psychological assumptions that underline our perception and understanding of the world around us by shaping our actions. Dweck $(2006,2017)$ asserted that since beliefs influence our ability to learn and therefore our growth, understanding mindsets offers a pathway for reaching higher levels of human capability by shaping a mindset of future positive possibilities. Buchanan and Kern (2017) extend Dweck's concepts of Fixed Mindset (emphasising one's innate, i.e. non-changeable gifts, as limiting our achievements) and Growth Mindset (focusing on effort to improve on one's achievements) to the Benefit Mindset (focusing on building on strengths to contribute meaningfully to a better future). These authors represent a purpose-driven mindset that everyday leaders follow in their quest to contribute to common good.

Kern, Waters, Adler and White (2014) started mapping various wellbeing constructs, noting the unique contributions from each construct in the overall measure of wellbeing. These authors then pioneered (Kern, Waters, Adler and White, 2015) a systematic research model to apply the multidimensional PERMA model of flourishing to school staff wellbeing by uncovering how PERMA dimensions are connected to self-reported life satisfaction, physical health, job satisfaction, and organizational commitment. Following on, Buchanan and Kern described how people can move along the continuum of 'Fixed' to 'Growth' mindset (Dweck, 2006) onto the 'Benefit Mindset': "a purpose-driven mindset that is redefining success from being the best in the world, to being the best for the world" (2017, p.2).

The present research responds to Buchanan and Kern's (2017) suggestion that Benefit Mindset has applications in education and psychology. These authors challenged social science researchers to explore change pathways for people to transform their mindset. We applied these principles for the first time (to the best of our knowledge) in the disability sector working with a group of parents raising children with disability or developmental delays.

\section{Connecting individual mindshift to collective good: Wellbeing, flourishing and empowerment}

Scott-Jackson and Mayo (2018) noted that the concept of engagement was developed in parallel by two very different streams. On the one hand, organisational writers studied engagement to understand how to harness previously untapped potential or effort from staff. Simon Sinek's "Start with Why" (2009) provided examples of how leaders inspired their followers to engage. The stories showcase how leaders uncover the purpose behind their actions and get audiences to identify with the meaning of their endeavours. Sinek's explanation of how leaders inspire followers into action outlined how important the search for meaning, one of the pillars of wellbeing, is in building this positive energy. On the other hand, psychologists showed how engagement could assist people become more positive. From their viewpoint of positive psychology research, these demonstrate that engagement is 
specific to individuals and intimately connected to wellbeing and mindset and embed this understanding into practical leadership tools. In their view, wellbeing principles can help leaders understand how to enthuse their followers by stimulating their positive energy.

Buchanan and Kern (2017) suggested extending Dweck's (2006) perspective to the context of collective leadership and purpose. This approach is congruent with Meadows' view (1999) that personal mindsets lie beneath systems and even little changes in mindsets can result in system-wide variations given the right leverage and Seligman's lead (2012) in pursuing collective rather than individual human flourishing. The present research followed this directive, using evidence from positive psychology. For instance parents are instructed to look for their child's strengths and their own as a basis for their flourishing. Parents in the program worked through a number of exercises, using tools that coach them to take their goals to action, and amongst other things, learnt how to approach their relationships with professionals from the perspective of their expertise as parents.

\section{The "epic" opportunity}

Cooperrider and Godwin's view (2015) is that many change management endeavours fail because leaders focus on overcoming people resistance to change. The authors posit that humans are wired for change and that what slows change is not resistance but a persistent 'deficit despair' that one's efforts will not create desired change. Parents raising children with disability report at time feeling that their child's progress is in the hands of experts (Heyworth, Mahmic \& Janson, 2017). This particular type of 'deficit despair' however can be overcome by instilling hope and confidence for change by connecting existing strengths, trial explicit strategies to reach identified goals and finding ways to sustain motivation to continue working towards the identified change. In his view, change starts by positively reframing a vision of the future into an "epic" opportunity - one that inspires others into action by kindling optimism and hope amongst them.

Cooperrider (2017) states that positive change is engaging, powerful and uplifting - it creates energy and motivation. Positive change thrives on wholeness, so to realize an epic opportunity one needs to unite stakeholders - rather than propose a change program that will be done to them. He proposes to use narratives that emphasise strengths and possibilities rather than deficiencies. Then individual discoveries can get compounded into collective energy around the epic opportunity that "strengthens the strength" on the canvas of possibilities. Seligman, Railton, Baumeister and Sripada (2016), described the emotional prospection mechanism, responsible for viewing into the future and documented its power to create positive mindsets.

The Now and Next ${ }^{\mathrm{TM}}$ program has pioneered the integration of Positive Psychology in the disability sector. With the support of thought leaders in research and development, parents trained as peer workers and participant observers. Peer facilitators engage in all stages of data collection and analysis, collating data in real time through bespoke applications to inform ongoing feedback ensuring maximization of program impact and reporting on family empowerment, agency and wellbeing through robust recognized measurements.

\section{Method}

\section{Participants and program}

Twenty-three participants (11 couples and one mother) raising young children with disability or developmental delays attended the Now and Next ${ }^{\mathrm{TM}}$ program, delivered over 4 half-day learning sessions. Run by trained parents/caregivers, the program supports participants to: (a) craft their inspiring vision for their family and child and for their personal development and (b) work on and achieve their goals. 
This program was launched in New South Wales in 2015 by two professionals with lived experience and evolved through co-design, rapid prototyping and ethnographic observations with the 300 families that have since completed it. Program facilitators are peers (that is, other parents of children with disability) trained to help parent-participants to support and motivate each other to explore opportunities for their children through a manualised and reproducible process. The program is further detailed by Heyworth, Mahmic and Janson (2017) and was evaluated by Moore, Fong and Rushton (2018).

The program distinguishes itself from other initiatives with parents as follows:

1. Implementing a novel approach: Setting a positive vision for our family future

2. Developing practical tools Family-Centered Practice: A whole family perspective

3. Rooted in positive psychology: Evidence-informed/research-based

4. Reaching optimum outcomes by parents learning to strengthen Parent-professional collaboration

5. Growing family empowerment within a peer group to celebrate achievements together

6. Promoting wellbeing practices to keep the (learning) cycles going: after goals are achieved, new ones are set.

The micro-interventions presented to participants were based on evidence-informed positive psychology methods:

A visioning process as a basis for prospection

Families engaged in prospection (Seligman, Railton, Baumeister \& Sripada, 2013) using Pictability ${ }^{\mathrm{TM}}$, an innovative bespoke visioning and planning tool. This fun and engaging process helps families to see new possibilities and set goals for their child, family and themselves. This individual visioning session provides parents with - sometimes their first experience of visioning a hopeful future for their son or daughter. At the conclusion of the visioning activity, peer facilitators assist participants in understanding how to link goal to outcomes and prioritise the goals to work on during their program. The following sessions focus specifically on a short-term goal for the participant's family, for their child, and a personal goal for themselves, to ensure they experience success through targeted and achievable thinking.

Developing Agency and Pathway

During the remaining 22 hours of the group sessions, families experiment with developing agency and strategies ('pathways') on their prioritised goals (Snyder, 2002). Sessions start with small group discussions for participants to reflect on their progress towards achieving their goals. Hence participants not only get acquainted with each others' goals, but they also experience giving and receiving feedback on agency and pathway building. These focused small group 'check in' discussions also allow each participant the opportunity to review their goals, reflect, and provide a forum in which to celebrate each goal achieved.

\section{Enhancing character strengths and building a wellbeing practice}

Participants identify their character strengths (Seligman, Steen, Park \& Peterson, 2005) so they can apply them in new contexts. When parents intentionally enroll their character strengths to develop strategies and plans, they 'lean in' to form more meaningful partnerships with professionals, engage with formal and informal supports, and learn which wellbeing practices best work for them. This micro-intervention focuses parents on how the practice of PERMA elements (Positive emotion, Engagement, Relationships, Meaning and Achievement) can increase their family's ability to flourish (Seligman, 2012). Facilitated discussions help parents understand the value of building better relationships with professionals to achieve better outcomes. Specifically, parents unpack how their 
understanding of their role in partnering with professionals evolves. For instance, they reflect on potential past incidents when deferring to professionals for expert advice, rather than trusting their own knowledge. Parents evaluate the agency increase that they experience during the program as they discuss specific instances.

The ethics process followed the guidelines set out by Early Childhood Intervention Australia Best Practice; all participants of the program were provided with an Information Sheet and Permission Form to gain their informed consent to collect data for research and evaluation purposes. The evaluation has been registered as Service Development Quality Improvement Register and all protocols relating to Quality Improvement projects have been adhered to.

\section{Measures}

The following tools were used to collect data through online survey administered at the start and the end of the session.

\section{Partners in Outcome Measures Scales (Duncan \& Reese, 2015) calculate participants'} engagement in a group program. For each session of the program, participants rated how they feel on 4 levels: Individual level (personal wellbeing), Interpersonal level (family, close relationships), Social level (work, school, friendships) and Overall (general sense of wellbeing). According to the 3 randomized control trials summarised by these authors, this measure incorporates the most robust predictors of group success into an outcome management system. Researchers 'partner' with participants to amplify their voice in service delivery input and feedback, through upfront, transparent discussions with participants about their scores, during and between sessions.

2. The Psychological Empowerment Scales for parents raising a child with disability from the Beach Center (Akey, Marquis \& Ross, 2000) includes 32 items. Validation of scores on the psychological empowerment scale takes into account attitudes of control and competence; cognitive appraisals of critical skills and knowledge; formal participation in organizations, and informal participation in social systems and relationships.

3 The Adult Hope Scale (Lopez \& Kerr, 2006) measures Snyder's cognitive model of hope. This model defines hope as "a positive motivational state that is based on an interactively derived sense of successful (a) agency (goal-directed energy), and (b) pathways (planning to meet goals)" (Snyder, Irving, \& Anderson, 1991, p. 287). The Adult Hope Scale contains 12 items. Four items measure pathways thinking, four items measure agency thinking, and four items are fillers. Participants respond to each item using an 8-point scale ranging from definitely false to definitely true. Agency and pathway scores can be interpreted individually as well as jointly forming the participants' Hope score.

4. Inspired from the wellbeing and flourishing approach (Forgeard, Jayawickreme, Kern \& Seligman, 2011), the 23 items of the PERMA profiler (Butler \& Kern, 2015) measure Positive (as well as negative) emotions, Engagement, Relationships, Meaning, Achievement, Health and Negative Emotions. The theory proposes that these elements can help people reach a life of fulfillment, happiness, and meaning.

5. Before the program ended, participants were asked to consider the question "What does the group mean to you?" and were asked to represent this as they see fit. Participants were divided into 2 groups, their performances were filmed and the content of these video materials were analysed. Video analysis has been particularly useful in analysing social interaction (Heath, 2011). Video clips were analysed using Büscher's methodology to test participants' 'shifting grounds' through their contribution to a group (2005). 


\section{Results}

\section{Flourishing}

On average, participants reported increases in PERMA factors measured as shown in Figure 1 below. A two-way repeated measures Analysis of Variance (ANOVA) showed that increases on the PERMA dashboard in Positive emotion, Engagement, Relationship, Meaning, Achievement and Health are small but significant $(F=9.20 ; \mathrm{df}=1 ; \mathrm{p}<.001)$ when comparing results before and after the Now and Next program.

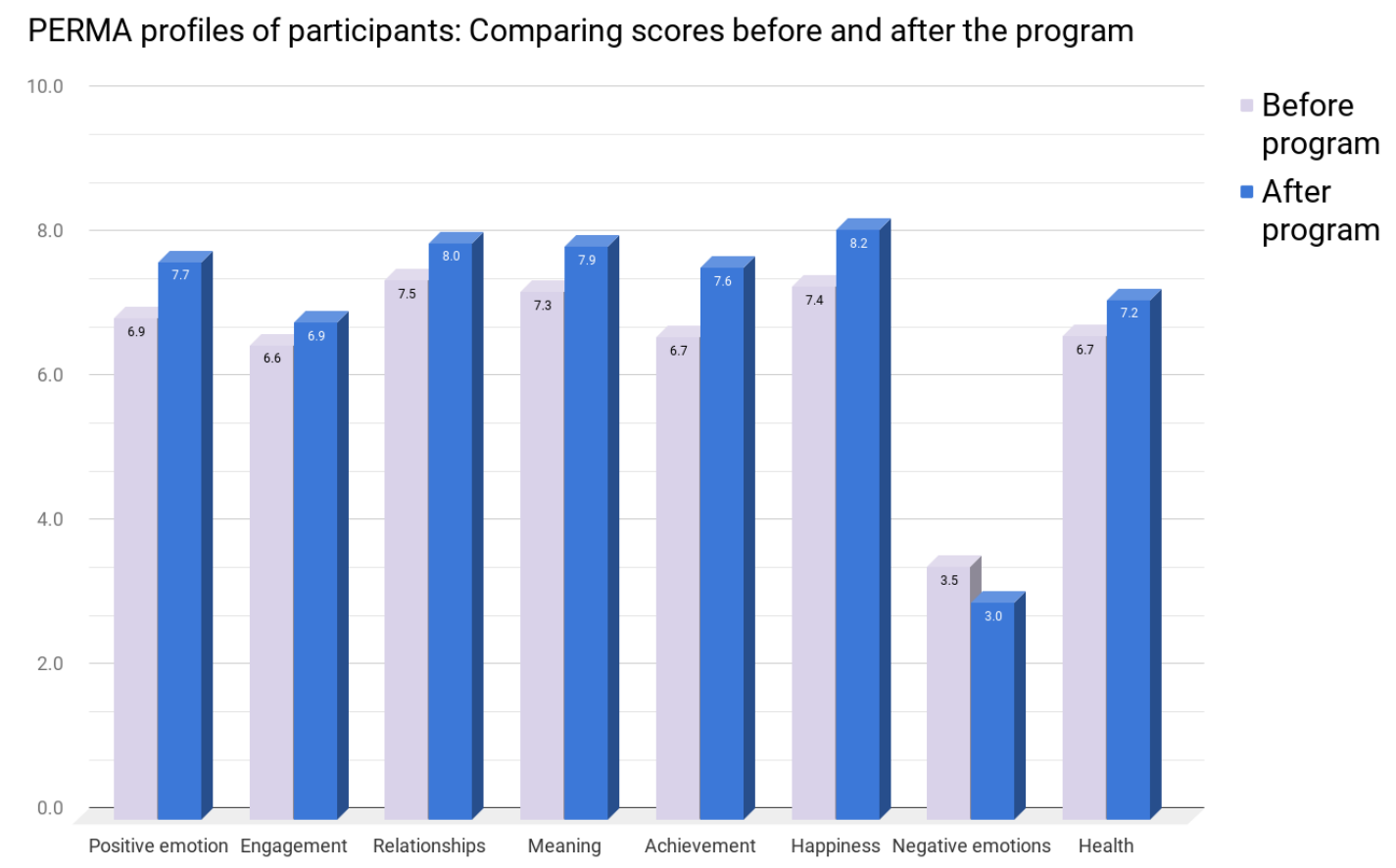

Figure 1: PERMA profiles before vs. after the group program

\section{Positive emotions}

Participants' increase of Positive emotions and decrease of Negative emotions measured by the PERMA profiler, was supported by their feedback about the program as follows:

Goals should not be based on past - look out into the future

In retrospect, our children can do lots more than what we worried about in the past - be positive and pay attention to the things our children can do now as they grow up

Feels like we have the resources and direction to move forward

Look out for the good

Remember what the PERMA dashboard teaches us: that different things can have different importance at different times - especially when it comes to caring for ourselves. We are in danger of burning out if we don't embrace our self-care!

\section{Engagement}

The aforementioned PERMA analysis showed that participants registered significant Engagement gain from the program. In addition, an indication of participants' engagement can be inferred through their ratings on the Partners in Change Outcome Measures (Figure 2), where measures on Individual, Interpersonal, Social and Overall sense of wellbeing registered increases that were statistically significant in an ANOVA test $(\mathrm{F}=8.8 ; \mathrm{df}=1$; $\mathrm{p}<.0005)$. 


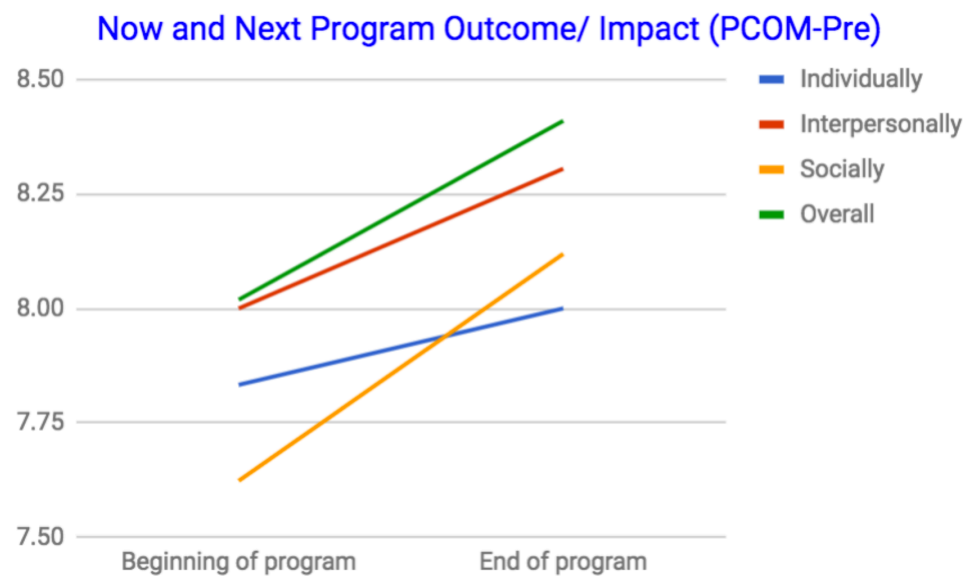

Figure 2: Partners in Change Outcome Measures ratings at the beginning vs. the end of the program

Participants reported gains in empowerment that more than doubled their scores from an average of 11.75 points $(\mathrm{SD}=14.4)$ to an average of 25.78 points $(\mathrm{SD}=10.2)$, hence gaining an average of 14.03 points (or $22 \%$ ) on the empowerment scale. This difference is statistically significant in a paired t-test $(\mathrm{t}=4.93 ; \mathrm{df}=19$; Standard error of difference $=2.4$; $\mathrm{p}<.001)$ consistent with how Fadda and colleagues (2017) view engagement. In addition to the above, qualitative examples of participants' thoughts about the value of engagement were:

I can actively support my wife as opposed to being reactive

If I get more engaged, there will be twice as much traction for our child's goals

I will support the expansion of this concept throughout New Zealand as much as I can in my professional capacity. I will recommend families attend where the Now and Next program is available. I will also contribute resources such as offering a venue for alumni to meet or for courses to be held if that is helpful to families. I will also strongly encourage fathers, grandfathers and brothers to participate in the program so they too can experience the empowerment of learning new skills, sharing their talents with others and creating hope for their family member with a disability.

\section{Relationships}

To complement the increase in the Relationships scale of the PERMA profiler, we examined participants' reflections about their relationships with the newly formed group as providing them with a sense of community. As an example of participants' perception of the role of relationships, we singled out the answers to their ratings on the Psychological Empowerment Scale about the sense of community they feel with other parents who have a child with a disability. Their ratings significantly increased from an average of 0.45 to an average of 1.13 points $(\mathrm{t}=2.32 ; \mathrm{p}<.001)$ as did their reported value of continuing to build a peer network (before the intervention: 65, after the intervention 84 , representing a $30 \%$ increase $(t=7.27$; $\mathrm{df}=17$, standard error of difference $2.64 ; \mathrm{p}<.001$ ).

Examples of participants' thoughts about relationships were:

Listening to others and realizing we are not alone - we can learn from each other

Dads need to get more involved

Getting your friends involved and helping them to understand our situation

If you are open to it, there is so much support out there, families and friends, formal and informal 
Ask questions to the professionals we work with!

[we learned...] good communication skills to work with professionals and in the home and the clarity that comes with them

People in our community need to know our children: the more this happens, the better off everyone is

Don't underestimate how much you can teach your friends and peers

\section{Meaning}

Participants chose to embody the meaning that the group held for them in short role-playing sessions. In addition to the meaning theme, a second theme emerged as participants' contribution to the group. This rich data provided multiple physical, relational and interactional indications about the meaning that the group took for them to fight off isolation, as a support mechanism for learning and going forward as well as a conduit for participation and contribution.

One group acted their transformational pathway first individually (each participant spatially separated from the others), then getting gradually closer and then close-knit - physically bringing their chairs and bodies together. The other group started off with participants holding arms acting a closeness to symbolise their support for each other. They followed by showing individuals attempting to isolate themselves from the group as a result of discouragement or feeling a loss of control. When this happened the group held tighter together so as to bring them back into the circle each time they doubted their own strength. This group also included the turning point moments when participants become conscious of their mindshift, and where many actually said in session: "we've got this", "What is my 'why?' I want to be able to help my child and family, but also other families. The group repeated "together we are stronger" backing up earlier comments that their "purpose is to contribute to our children's progress, to other families and to the disability sector as a whole'. The following comment was also made:

There is strength in collective energy and shared experiences. When people are brought together for a common reason there is an initial aloofness in their interaction with each other. But as they open up and share their thoughts, struggles and unique experiences about their disabled child, bonds are created that enables a space of energy and love. This group demonstrated that they will always have a bond and despite the many pathways their lives will take, they will pick up exactly where they left off whenever they connect via Facebook, alumni gatherings or working together perpetuating the Now and Next journey for others.

\section{Achievements}

Facilitators record in real time the short-term goals that parents prioritized which are achieved during the program. On average, participants achieved $89 \%$ of their goals. All $(100 \%)$ of the Child goals were achieved by session 3, 100\% of the Family goals were achieved by session 2 and $81 \%$ of the Personal goals were achieved by session 4 , with the remaining participants committing to pursue theirs in the weeks following the end of the program.

Figure 3 shows how the goal category percentages compare in the different goal types. Child goals categories were: Wellbeing (36.4\%), Communicating (36.4\%), followed by Contribution, Belonging and Exploration (each at 9.1\%), as rated using the local Early Intervention curriculum framework (Ministry of Education, 2017). Wellbeing goals constituted the largest category chosen $(41.7 \%)$, followed by Spending quality time together (41.7\%) and Relationships (16\%) for Family Goals. Finally, for Personal Goals, once again, the largest goal theme was Wellbeing (63.6\%), followed by Career goals $(18.2 \%)$ and Fitness goals (18.2\%). 


\section{Goal Categories Segmentation}

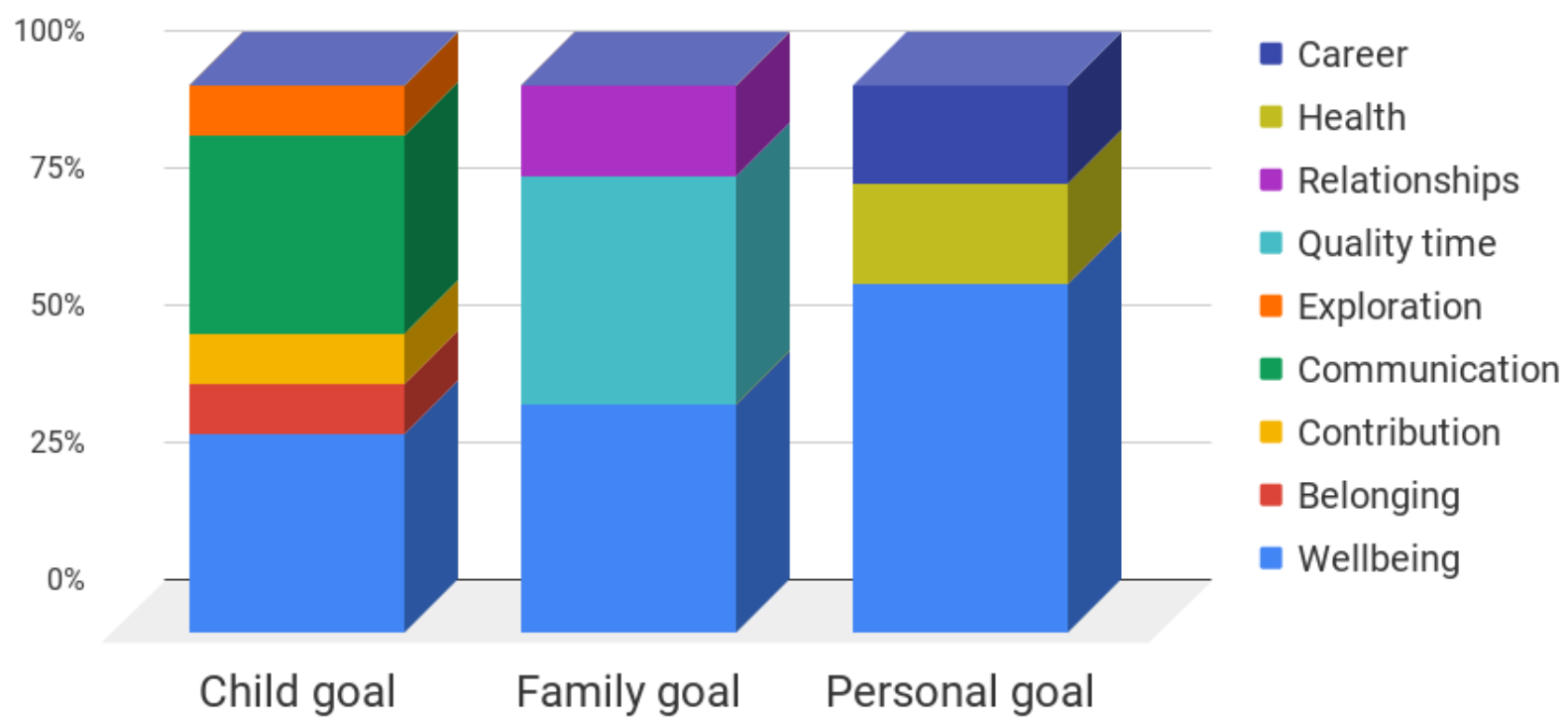

Figure 3: Goals Categories comparisons

Participants' reflected about their learning about goal setting and achievement as follows: The integration of the PERMA elements makes more sense now after we got to work on our short-term goals and get to "A" - achieve them

The power of sharing our goals - gets buy in and keeps us accountable!

Unpack a long-term goal into short-term goals (steps) that are achievable

Remember even small achievements... even when we're very tired or in a low

Beware of the trap we set for ourselves - moving the goal post! "We've done this BUT..." Buts can be a warning sign. Rather switch from being just aware of what your child has done to celebrating small achievements

I took the learning from this group to my child's Individual Planning session last week, and feel I will carry on using the tools we learnt going forward

\section{PERMA profiles and action-oriented outcomes}

PERMA profiles were compared for participants along the two following action-oriented outcomes:

a. Hope as a personal action-oriented stance: Snyder's (2002) Hope theory posited that hope is made up of the goals we set for ourselves, the pathways or strategies we trial and put in place to work towards these goals and the agency to act in order to get results. Participants' levels of hope before the program (50.23) increased (63.22) significantly after the program $(\mathrm{t}=10.9 ; \mathrm{df}=16$; Standard error of difference $=1.19 ; \mathrm{p}<.001)$.

b. Community building as a group action-oriented intent: as reported in the relationship section above, participants recorded a significant increase of $30 \%$ in their intent to continue building a peer network after the program. An in-session observer noted: 
As the sibling of a person with a disability and also as a professional working in the New Zealand disability sector I have often reflected on the interaction between professionals and families/whānau ${ }^{1}$. I have seen many examples where the whānau/agency interface has worked well and also many examples where it hasn't. Some of these experiences have occurred as a supporter of my disabled sibling and our parents and at other times as a professional.

Following Kern, Waters, Adler and White's (2014) method to compare wellbeing profiles of participants who score on the highest vs. the lowest quartile for an outcome measure, we built PERMA profiles of participants in the highest vs. the lowest quartiles of these two action-oriented outcomes. Figure 4 displays different PERMA profiles for participants who most believed that continuing to meet with the newly formed peer network would be beneficial to their families (in the highest quartile of this distribution) as compared to the ones who least believed in the value of continuing to meet with their new network (in the lowest quartile of this distribution). Figure 5 shows the difference in PERMA profiles of participants in the highest quartile of the hope value distribution as compared to the ones in the lowest quartile of this distribution. These two Figures show that the high groups markedly higher on each of these domains (this pattern is inversed for negative emotion), and further, that different PERMA factors profiles differentiate the two outcomes under assessment. For both the individual hope and group community building action-oriented outcomes, we uncovered similar types of PERMA profiles. The advantage of profiles (as opposed to single scores) is that the former give an indication of where it is possible to act and create change.

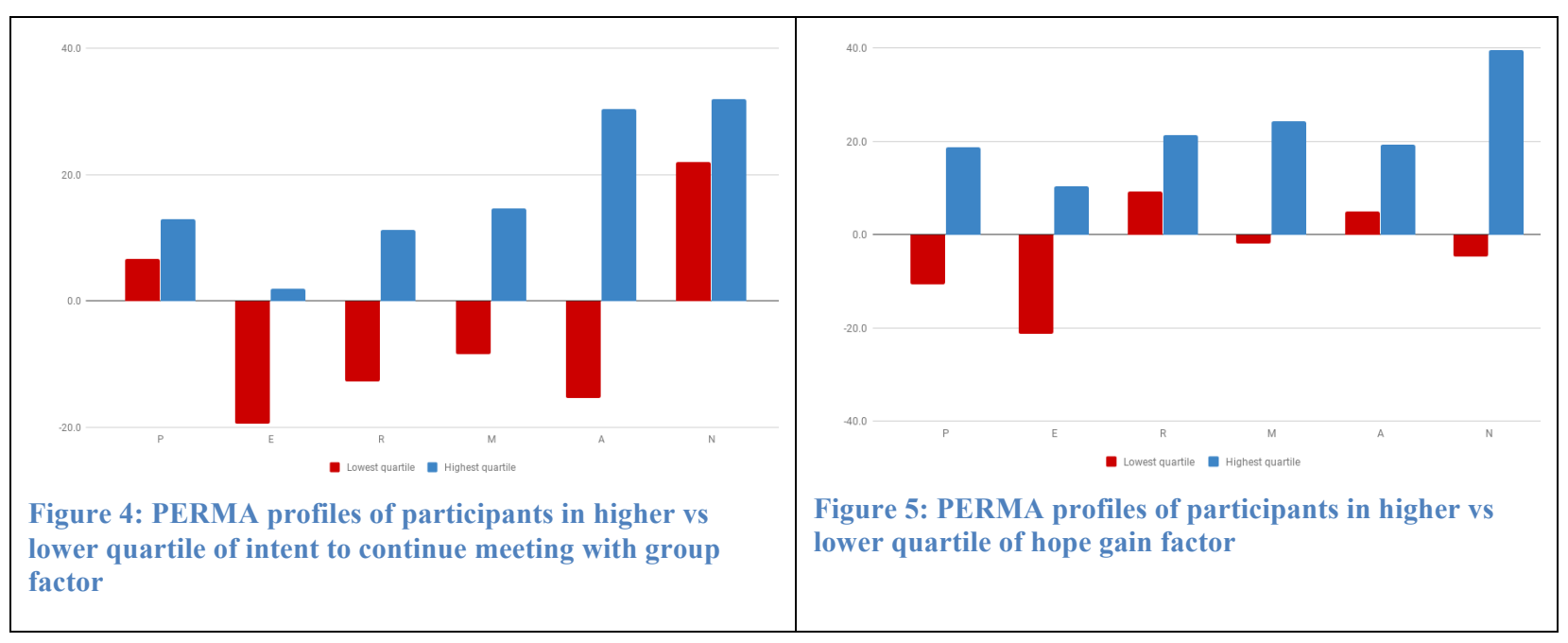

Supporting this point, participants noted amongst others:

Collectively the group is very diverse and we support each other

Let's not loose momentum from the energy we are experiencing in this group to get to the next stages of developing this movement

\section{Contributing and building community}

The other outcomes that emerged at group level were about building more effective collaborations between practitioners, parents and community builders.

The early intervention host practitioner entered the partnership with an intention to invest in parent capacity building. This linked to their internal evaluation to build onto their familycentred practice by intentionally involving parents in program planning and intervention. The host organisation has adopted a goal to action planning tool and peer workforce development, which fits with their strategic aims.

\footnotetext{
${ }^{1}$ Whānau is the Maori word for extended family, which the New Zealand indigenous community considers as the family unit.
} 
The host organisation adopted one of the program's coaching tool to assist families bring their goals to action (Mahmic \& Janson, 2018) and have proceeded to carry out a research project which involved parents and a grandparent's contribution. Additionally the host organisation and parents have continued to work together to incubate the peer network with service design. Some immediate concrete actions to embed this purpose were: co-presenting at national and international conferences, parents planning, running and presenting at an early intervention conference and co-design work to start building a peer workforce. Parents decided to continue meeting beyond the program end to build a national New Zealand peer network to join the Australian alumni group, but also to act nationally.

The alumni group's initial ideas were to:

- Continue to support each other

- Explore how they can assist other parents

- Provide a parent voice to the sector and decision-makers - for instance with representation at a local District Health Board.

What the alumni group seeks to contribute to other parents was described as:

- Become more confident in choosing inclusive schooling options, and engaging constructively and collaboratively with educators to support their children's learning and wellbeing

- Become more active in planning for their children to transition successfully from school to further education and training, and meaningful roles and employment in the community, rather than assuming they are destined for long-term benefits and day programs.

When asked why being part of an alumni group is important to them, parents answered:

- It builds strength between families which is important for an ongoing support structure

- It gives a sense of belonging when so often having a child with a disability can feel quite isolating

- It builds a network to provide education and ideas to help our children

- It is a group of families with a shared goal to, not only support each other and their children, but to change the way people see others with disabilities and to make the world a more inclusive place.

\section{Discussion}

Why work on empowerment and building hope with parents who raise a child with disability or developmental delay? It has often been said that we cannot solve today's problems with yesterday's solutions. The disability sector has not yet developed approaches to support these parents with reliable impact. Societal flourishing is one of our most basic social innovation challenges, hence rather than wait for solutions to be applied to them, some user groups are taking the lead and co-designing the solutions that work for them. These empirical findings support the introduction of positive psychology in the disability sector on philosophical grounds: wellbeing features as the most often chosen category when unpacking the goals that parents chose through a process which they deemed more authentic and leading to richer goals for their children, their families and themselves (Moore, Fong \& Rushton, 2018): Wellbeing goals represented $36.4 \%$ of Child; $41.7 \%$ of Family; and $63.6 \%$ of Personal goals.

In radically re-thinking our approach to disability, we were confronted with the reality that the disability sector is lagging behind other health-related sectors in their application of 
findings from positive psychology and the importance of flourishing and wellbeing. Harnessing previously untapped talent works the same for parents as it works for organisations looking to enhance employee engagement. Empowering parents has the potential to have a long lasting domino effect on children and family outcomes - hence the importance of starting as early as possible.

\section{Positivity as an engine for individual change}

Seligman, Railton, Baumeister and Sripada (2016) postulated that prospection allows one to predict some of the circumstances one will encounter from the multiple alternative outcomes that could unfold. In their view, the mind mostly engages with the future and is not necessarily a captive of the past, as early psychological theories posited. They view emotional prospection as an engine for action. The appreciation of individual behavior, perception and memory goes through the understanding of prospection. Setting and achieving goals provides parents with ongoing learning experiences of reconsidering recollections and visualising future opportunities. Our emotional life not only responds to the present but also provides guidelines and aspirations that direct future behavior. The present research measured positivity through the PERMA's Positive (and Negative) emotions scales, however in addition to these were some elements which were also defined as having a positive value and an added component of activity. Another way to appraise engagement has been through parental empowerment research such as that carried out by Fadda and colleagues (2017). According to these authors, self-determination and competence underlie empowerment, and play a complementary role in fostering engagement, thus supplement the operational definition of empowerment as laid out by Akey, Marquis and Ross (2000) and demonstrating the relevance of our findings that participants reported gains in individual empowerment. Our empowerment findings are consistent with Rosenbaum and Ronen's (2013) view that empowering parents is an essential part of children's development and that the most important goal of practitioners is the "long term developmental, functional and life quality outcomes of children [...] and the well-being of their families" (p. 72). Components of positively charged 'active ingredients' are also found in Hope and PERMA measures. The Hope measure (Snyder, 2002) is composed from the strategies (pathways) to pursue goals and the belief (agency) in one's capacity to act to achieve goals. Adding to this, Seligman (2012) conception of the Meaning value of PERMA as coming from serving a cause bigger than oneself, further endows it with qualities reinforcing action.

These results support the review done by Forgeard, Jayawickreme, Kern and Seligman (2011) conceptualising the pursuit of wellbeing as an active process and that policy makers need to consider as one of their main concerns the measurement and improvement of flourishing, bringing these concepts into the collective space.

\section{Group self-transformation towards a Benefit Mindset}

Participants actions about building and contributing to community are 'above board' outcomes in terms of Benefit Mindset and complement in a meaningful ways self reports of (i.e. inferred) wellbeing, hope and engagement. Furthering the latter individual psychological indicators, the group's decisions to form an entity in order to take action represent concrete manifestations of outcomes from a shared Benefit Mindset. The description of the activities planned by the alumni group extends to the collective level Buchanan and Kern's (2017) definition of the Benefit Mindset:

[...] what it means to learn and lead to achieve and collectively contribute. From this perspective the key question that everyday leaders ask themselves is not how they can flourish in isolation, but rather, how we can all come together and become partners in each other's flourishing. They recognize that our ability to flourish is deeply interrelated with the communities and ecosystems to which we belong (p.6). 
Video data analysis supported the above reported findings about the meaning that participants attributed to their community engagement. Extending Büscher's (2005) and Heath's (2005) results about visual methods offering alternative communication means for research participants, the latter expressed commonality of aims and spirit, not just in words, but also in space and through activity.

Taken together these results show that throughout their learning, parents describe experiencing an energy boost when experimenting with applying positive psychology principles to their lives. When asked "how come you have so much energy to contribute to a peer group?" many of their answers encapsulate perhaps the greatest waste of precious resources when it comes to creating progress for their children: "I've never been asked to help before." These findings present the value of teaching parents an evidence-based curriculum to build positivity and agency piece by piece, which is different from traditional peer support groups where learning may loosely occur according to the topics that people bring up for open-ended discussions, but over which facilitators have little control. These findings document how a collective positive mindset can emerge from group activity.

\section{Framework for analysis}

These alumni have clearly expressed that their individual flourishing is deeply interconnected to collective flourishing, congruent with Buchanan and Kern (2017). It is seen in the intentions and actions of the alumni group that are all about sharing their learning and energy with others. We suggest that what applies here is Cooperrider and Fry's (2012) view that as people come together for an exciting common good this collective flourishing connect to the PERMA pillars through a phenomenon they coined 'mirror flourishing' where people move beyond words to the actions that produce the outcomes that they are inspired by. This framework originally developed for large group also applies in the context of a relatively small group - albeit one that aspires to grow very large. Cooperrider's (2017) theory of change is inspired by Design Thinking and rapid prototyping: as participants visualise the change, it can be felt rapidly and build momentum. In his view, successful change is a combination of strengths, purpose and collaboration leading to positive contagion.

An example of this is the position statement on parent/professional partnerships that another alumni group who graduated from this program produced at their recent conference, and which emphasises the responsibility of families to lead, partner and contribute (Heyworth, 2017). This contrasts with potential parents' expectations that professionals and educators hold primary responsibility for their children's outcomes, and leads to excess demand for scarce and costly specialist supports. Participants talked about the liberating impact of the mindshift that they experienced by focusing on strengths. These findings extend the Solution-Focused Coaching perspective, which nurtures an interactive learning process that ultimately impacts on parents' engagement, empowerment and enhanced capacity and community participation (Graham, Roger \& Kennedy-Behr, 2017; King, Schwellnus, Servais \& Baldwin, 2017).

The Benefit Mindset concept guides our examination of how our attitudes and actions affect others so that the decisions we take are tactically based on mutual advantage. There are indications that this alumni group has developed a Benefit Mindset because it chose to share knowledge for the common benefit to the disability community. Hence, these findings contribute to assembling a picture of growing positivity as a basis for action amongst participants. In these families' view, leadership is not an option - it is their responsibility. 


\section{Implications}

To our knowledge, this is the first account of the way families raising a young child with disability or developmental delay developed a Collective Benefit Mindset to achieve better outcomes. As parents formulated the progress that they identified for their children they collectively realised that with the tools they learnt, they could finally make a difference to their children but also to other families raising children with disability. When families in this situation seize such 'epic' opportunity (Cooperrider \& Goodwin, 2015) to radically change their perspective, they can leave behind old attitudes of 'deficit despair'. They can become more empowered and committed to forming positive working relationships with professionals (Kendrick, Ward \& Chenoweth, 2017). They can also build on their strengths as they are the experts in their children's and families' wellbeing, creating novel outcomes in parallel.

\section{Limitations}

The findings described in the present article are specific to a single program, and care should be taken when generalising to other programs and delivery formats. However, the details provided about the perspectives of the participants should enable practitioners to draw parallels about the relevance of these results to other parent groups, while at the same time offering insights into the implementation of such programs.

Findings reported here about a relatively small group of parents are congruent with those reported for 150 participants of this program by Moore, Fong and Rushton (2018) whose evaluation confirmed significant gains of empowerment, hope and PERMA levels as participants' outcomes. In considering the implementation of wellbeing programs for parent groups, a note of caution should be raised. Teaching parent the practice of wellbeing is of central priority to the Now and Next program and is emphasised both in the group learning curriculum and in its session applications. Results about parent empowerment, hope and PERMA levels may well differ for parent groups which do not prioritise wellbeing to the same extent. Future longitudinal research is needed to understand how a group can transform its mindset to extend its reach into the community and sustain its impact.

\section{Conclusion}

As resources invested in the disability sector are limited, it is crucial for policy makers and practitioners to understand how to harness the unrecognised - yet powerful and positive Benefit Mindset that parents bring to the sector and that has largely remained untapped to date. This research adds a piece of evidence, which has largely been missing in this body of literature: the families' Collective Benefit Mindset in their voice.

\section{References}

Akey, T.M., Marquis, J.G. \& Ross, M.E. (2000). Validation of scores on the psychological empowerment scale: A measure of empowerment for parents of children with a disability. Educational and Psychological Measurement, 60(3), 419-438.

Buchanan, A., \& Kern, M. L. (2017). The benefit mindset: The psychology of contribution and everyday leadership. International Journal of Wellbeing, 7(1).

Büscher, M. (2005) Social life under the microscope? Sociological Research Online, 10. Retrieved August 2018: http://www.socresonline.org.uk/10/1/buscher.html.

Butler, J. \& Kern, M. L. (2015). The PERMA-Profiler: A brief multidimensional measure of flourishing. Available from http://www.peggykern.org/questionnaires.html 
Campbell, A., Converse, P. E., \& Rodgers, W. L. (1976). The quality of American life: Perceptions, evaluations, and satisfactions. Russell Sage Foundation.

Cantril, H. (1965). The patterns of human concern. New Brunswick, NJ: Rutgers University Press.

Case, S. (2000). Refocusing on the parent: What are the social issues of concern for parents of disabled children? Disability \& Society, 15(2), 271-292.

Cooperrider, D. (2017). Managing-as-Designing in an Era of Massive Innovation: A Call for Design-Inspired Corporate Citizenship 1. In Globalization and Corporate Citizenship: The Alternative Gaze (pp. 53-66). Routledge.

Cooperrider, D. L., \& Godwin, L. N. (2015). Feature Choice. AI Practitioner, 17(3).

Diener, E., Wirtz, D., Tov, W., Kim-Prieto, C., Choi, D. W., Oishi, S., \& Biswas-Diener, R. (2010). New well-being measures: Short scales to assess flourishing and positive and negative feelings. Social Indicators Research, 97(2), 143-156.

Duffy, S. (2003). Keys to citizenship: A guide to getting good support services for people with learning difficulties. Paradigm Consultancy \& Development Agency Limited.

Duncan, B. \& Reese, R.J. (2015). The Partners for Change Outcome Management System: The client's frame of reference revisited. Psychotherapy: Theory, Research, Practice, Training, 52, 391-401.

Durand, M., \& Smith, C. (2013). The OECD approach to measuring subjective well-being. World happiness report, 2013, 112-137.

Dweck, C. (2017). Mindset: changing the way you think to fulfill your potential. Hachette UK.

Fordyce, M.W. (1988). A review of research on the Happiness Measures: A sixty second index of happiness and mental health. Social Indicators Research, 20, 355-381.

Forgeard, M. J., Jayawickreme, E., Kern, M. L., \& Seligman, M. E. (2011). Doing the right thing: Measuring wellbeing for public policy. International Journal of Wellbeing, 1(1).

Available at:

https://internationaljournalofwellbeing.org/ijow/index.php/ijow/article/viewFile/15/86

Graham, F., Rodger, S., \& Kennedy-Behr, A. (2017). Occupational Performance Coaching (OPC): Enabling caregivers' and children's occupational performance'. Occupation-centred practice with children: A practical guide for occupational therapists. 2nd edn. West Sussex, UK: Wiley-Blackwell, 209-232.

Heath, C. (2011). Embodied action: video and the analysis of social interaction. Qualitative research, 250-270.

Hervás, G., \& Vázquez, C. (2013). Construction and validation of a measure of integrative well-being in seven languages: The Pemberton Happiness Index. Health and quality of life outcomes, 11(1), 66 . 
Heyworth, M. Mahmic, S. \& Janson, A. (2017) Now and Next: A radically new way to build peer leadership in families raising young children with disability or developmental delay. http://www.ijdcr.ca/VOL15_01/index.shtml

Hone, L. C., Jarden, A., Schofield, G. M., \& Duncan, S. (2014). Measuring flourishing: The impact of operational definitions on the prevalence of high levels of wellbeing. International Journal of Wellbeing, 4(1).

Iasiello, M., Bartholomaeus, J., Jarden, A., \& Kelly, G. (2017). Measuring PERMA+ in South Australia, the State of Wellbeing: A comparison with national and international norms. Journal of Positive Psychology and Wellbeing, 1(2), 53-72.

Kahneman, D. \& A. Deaton, A. (2010) High income improves evaluation of life but not emotional well-being," Proceedings of the National Academy of Science, 107, 16489-493.

Kendrick, M., Ward, M. \& Chenoweth, L. (2017): Australia's national disability insurance scheme: looking back to shape the future, Disability \& Society. 32(9), 1333-1350.

Kern, M. L., Waters, L., Adler, A., \& White, M. A. (2014). Assessing employee wellbeing in schools using a multifaceted approach: Associations with physical health, life satisfaction, and professional thriving. Psychology, 5(06), 500.

Kern, M. L., Waters, L. E., Adler, A., \& White, M. A. (2015). A multidimensional approach to measuring well-being in students: Application of the PERMA framework. The journal of positive psychology, 10(3), 262-271.

King, G., Schwellnus, H., Servais, M., \& Baldwin, P. (2017). Solution-focused coaching in pediatric rehabilitation: investigating transformative experiences and outcomes for families. Physical \& occupational therapy in pediatrics, 1-17.

Mahmic, S. \& Janson, A. (2018) Now and Next: An innovative leadership pipeline for families raising young children with disability or delay. Centre for Welfare Reform. Available from: http://www.centreforwelfarereform.org/library/by-az/now-and-next.html

Fadda, M., Galimberti, E., Romano, L., Faccini, M., Senatore, S., Zanetti, A. \& Schultz, P.J. (2017). Validation of a scale to measure parental psychological empowerment in the vaccination decision. Journal of public health research, 6(2).

McEwen, C. A., \& Schmidt, J. D. (2007). Leadership and the corporate sustainability challenge: Mindsets in action.

Meadows, D. (1999). Leverage points. Places to Intervene in a System. Hartland, VT: Sustainability Institute.

Mellor, D., Stokes, M., Firth, L., Hayashi, Y., \& Cummins, R. (2008). Need for belonging, relationship satisfaction, loneliness, and life satisfaction. Personality and individual differences, 45(3), 213-218.

Moore, T., Fong, M., \& Rushton, S. (2018). Evaluation: Now and Next program. Plumtree Children's Services, Inc. \& Murdoch Children's Research Institute. Parkville, VIC: Centre for Community Child Health. 
Ministry of Education. (2017).Te Whariki: he whariki matauranga mongamokopuna o Aotearoa: Early childhood curriculum. Retrieved fromhttps:/education.govt.nz/assets/Documents/Early-Childhood/ELS-Te-Whariki-EarlyChildhood-Curriculum-ENG-Web.pdf

Rosenbaum, P.L. \& Ronen, G.M. (2013). A developmental perspective on childhood neurological conditions. In: Ronen, G. M., Ronen, G. M., \& Rosenbaum, P. L. (Eds.). Life quality outcomes in children and young people with neurological and developmental conditions: concepts, evidence and practice. Mac Keith Press.

Scott-Jackson, W., \& Mayo, A. (2018). Engagement, Happiness and Well-Being: Why Bother? In Transforming Engagement, Happiness and Well-Being (pp. 1-12). Palgrave Macmillan, Cham.

Seligman, M. E. (2012). Flourish: A Visionary New Understanding of Happiness and Wellbeing. New York: Simon and Schuster.

Seligman, M. E., Railton, P., Baumeister, R. F., \& Sripada, C. (2016). Homo Prospectus. London, UK: Oxford University Press.

Sinek, S. (2009). Start with why: How great leaders inspire everyone to take action. Penguin.

Snyder, C. R., Harris, C., Anderson, J. R., Holleran, S. A., Irving, L. M., Sigmon, S. T., et al.(1991). The will and the ways: Development and validation of an individual-differences measure of hope. Journal of Personality and Social Psychology, 60, 570-585.

Snyder, C. R. (1994). The psychology of hope: You can get there from here. New York: Free Press.

Snyder, C. R. (2002). Hope theory: Rainbows in the mind. Psychological Inquiry, 13, 249275.

Wilson, K. G., Sandoz, E. K., Kitchens, J., \& Roberts, M. (2010). The Valued Living Questionnaire: Defining and measuring valued action within a behavioral framework. The Psychological Record, 60(2), 249-272. 